
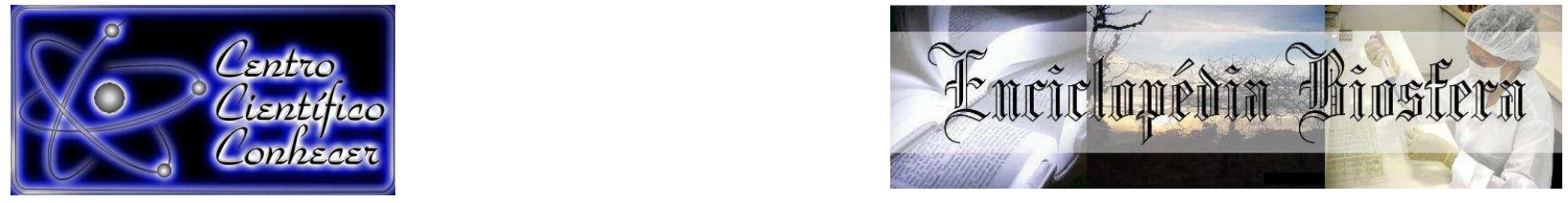

\title{
AMBIENTES E SUBSTRATOS NA PRODUÇÃO DE MUDAS DE PATA DE VACA (Bauhinia forficata Link).
}

\footnotetext{
Helena Souza Ronchi ${ }^{4}$, Filipe Pereira Giardini Bonfim ${ }^{1}$; Adelana Maria Freitas Santos $^{2}$; Francisco José Domingues Neto ${ }^{3}$, Bruna Lima Bloch Telles Alves ${ }^{5}$.

${ }^{1}$ Professor Assistente Doutor do Departamento de Horticultura, FCA, UNESP Botucatu, São Paulo, Brasil.

2 Doutora em Programa de Pós Graduação em Agronomia: Horticultura, FCA, UNESP Botucatu, São Paulo, Brasil.

${ }^{3}$ Doutorando em Programa de Pós Graduação em Agronomia: Horticultura, FCA, UNESP Botucatu, São Paulo, Brasil.

${ }^{4}$ Mestranda em Programa de Pós Graduação em Agronomia: Horticultura, FCA, UNESP Botucatu, São Paulo, Brasil. E-mail: hsronchi@gmail.com .

${ }^{5}$ Graduanda em Engenharia Florestal, FCA, UNESP Botucatu, São Paulo, Brasil.
}

Recebido em: 08/04/2016 - Aprovado em: 30/05/2016 - Publicado em: 20/06/2016 DOI: 10.18677/Enciclopedia_Biosfera_2016_005

\begin{abstract}
Existem diversos fatores que influenciam o processo de formação de mudas de qualidade, dentre os principais estão o tipo de substrato e o ambiente. Nesse sentido, objetivou-se avaliar o efeito de diferentes substratos e ambientes para a formação de mudas de Bauhinia forficata Link. O delineamento experimental utilizado para diferentes ambientes foi inteiramente casualizado, com três tratamentos e sete repetições, sendo estes: estufa plástica fotosseletiva com $30 \%$ de sombreamento; tela de sombreamento com malha de $50 \%$ e céu aberto. Enquanto que para diferentes substratos, com cinco tratamentos e quatro repetições, sendo: Tropstrato ${ }^{\circledR}$; Fibra de coco; Solo puro; Solo + Composto orgânico (esterco de curral curtido) (3:2) e Solo + Composto orgânico + Areia (3:2:1). As plantas foram avaliadas quanto à porcentagem de germinação $(P G)$, índice de velocidade de emergência (IVE), área foliar (AF), comprimento da raiz (CR) e da parte aérea (CPA), massa fresca e seca da raiz (MFR; MSR), caule (MFC; MSC) e folha (MFF; MSF), volume da raiz (VR) e índice SPAD. Os diferentes substratos utilizados não apresentaram diferenças quanto à porcentagem de germinação (PG), índice de velocidade de emergência (IVE), área foliar (AF), comprimento da raiz (CR) e da parte aérea (CPA), massa fresca (MFR), caule (MFC) e folha (MFF). Já para a massa seca da raiz (MSR), massa seca do caule (MSC) e volume da raiz (VR) houve diferença significativa entre os substratos utilizados. Para os diferentes ambientes observaram diferenças nas variáveis de índice de velocidade de emergência (IVE), comprimento do caule (CC), massa de matéria seca da raiz (MSR) e massa de matéria seca da folha (MSF), observaram-se diferenças significativas.
\end{abstract}

RESUMO

PALAVRAS -CHAVE: espécies medicinais, espécies nativas, mudas. 


\title{
SEEDLINGS PRODUCTION Bauhinia forficata Link: EFFECT OF ENVIRONMENTS AND SUBSTRATES
}

\begin{abstract}
There are several factors that influence the process of formation of quality seedlings, among the main ones are the type of substrate and the environment. In this sense, the objective of this study was to evaluate the effect of different substrates and environments for the formation of seedlings Bauhinia forficata Link. The experimental design for different environments was completely randomized, with three treatments and seven repetitions, namely: plastic greenhouse photoselective with $30 \%$ shade; shading screen mesh of $50 \%$ and open. While for different substrates, with five treatments and four repetitions: Tropstrato ${ }^{\circledR}$; Coconut fiber; Solo pure; Soil + organic compound (cow manure) (3: 2) and soil organic compound ++ sand (3: $2: 1)$. The plants were evaluated for germination percentage (PG), emergency speed index (IVE), leaf area (AF), root length (CR) and shoot (CPA), fresh and dry root (MFR ; MSR), stem (MFC; MSC) and leaf (MFF; MSF), volume root (VR) and SPAD index. The different substrates showed no differences in PG, IVE, AF, CR, CPA, MFR, MFC and MFF. As for the MSR, MSC and VR was no significant difference between the substrates used. For the different environments there were no significant differences for PG, AF, CR, MFR, MFC, MFF, MSC, VR and SPAD index, while for the IVE, DC, MSR and MSF, there were significant differences.
\end{abstract}

KEYWORDS: medicinal species, native species, seedling production.

\section{INTRODUÇÃo}

Conhecida como pata de vaca, a espécie Bauhinia forficata Link (Fabaceae) é largamente utilizada na medicina popular por possuir propriedades hipoglicemiantes comprovadas por meio de pesquisas farmacológicas, assim como em diversos tratamentos para inflamações renais (LORENZI, 2002). A infusão das folhas desta espécie é utilizada predominantemente no tratamento do diabetes mellitus, sendo ainda empregada como agente diurético, tônico e depurativo (SANTOS \& RIEDER, 2013; LOPEZ \& SANTOS, 2015).

É considerada espécie nativa da América do Sul e no Brasil encontra-se na região sob o domínio do bioma Mata Atlântica, concentrando, principalmente, nos estados do sudeste e sul. Trata-se de uma árvore pioneira, com rápido crescimento, e com alta taxa de sobrevivência no campo, sendo indicada para plantios de florestas nativas (TRES \& REIS, 2009). Porém, mesmo com a alta taxa de sobrevivência, para que a planta se estabeleça no campo, é imprescindível a obtenção de mudas de qualidade.

A qualidade das mudas é fator fundamental para o sucesso de povoamentos florestais, motivo pelo qual se busca produzir mudas de qualidade (FERRAZ \& ENGEL, 2011; SILVA et al.,2012). Vários fatores afetam o processo de formação de mudas, dentre eles, técnicas adequadas associadas à: irrigação, nutrição, substratos e recipientes. (COSTA et al., 2011a).

No momento da escolha do substrato como um meio de crescimento de mudas, devem ser consideradas algumas características físicas e químicas relacionadas com a espécie produzida, pois as mesmas exercem grande influência na arquitetura do sistema radicular e no estado nutricional

ENCICLOPÉDIA BIOSFERA, Centro Científico Conhecer - Goiânia, v.13 n.23; p.51 2016 
das plantas (MORAES et al., 2012). Mudas com o sistema radicular bem desenvolvido estão mais preparadas para competir com as plantas invasoras logo no início da implantação e, portanto, tendem a apresentar maior sobrevivência pósplantio (LELES et al., 2001).

Outro fator que afeta a produção de mudas é o ambiente, o qual interfere na temperatura, umidade e luminosidade. A produção de mudas em ambientes protegidos, como estufas agrícolas e telas de sombreamento, proporciona melhores condições de desenvolvimento da planta e, consequentemente, melhores produções a campo (COSTA et al., 2010). Modificações nos níveis de luminosidade podem acarretar diferentes respostas em suas características fisiológicas, bioquímicas, anatômicas e de crescimento. Assim, a eficiência do crescimento pode estar relacionada à habilidade de adaptação das plantas às condições de intensidade luminosa do ambiente (KOZLOWSKI et al., 1991; ATROCH et al., 2001).

Nesse sentido, objetivou-se estimar o efeito de diferentes substratos e ambientes na produção de mudas da espécie Bauhinia forficata Link.

\section{MATERIAL E MÉTODOS}

\section{forficata Link.}

- Diferentes ambientes na produção de mudas da espécie Bauhinia

O delineamento experimental utilizado foi inteiramente casualizado com três tratamentos e sete repetições. Os tratamentos foram constituídos por diferentes ambientes para a produção de mudas, sendo: estufa plástica fotosseletiva com $30 \%$ de sombreamento; tela de sombreamento com malha de $50 \%$ e céu aberto. Os resultados da temperatura e umidade dos ambientes encontram-se na Tabela 1.

TABELA 1. Temperatura e Umidade média dos ambientes de produção de mudas de pata de vaca.

\begin{tabular}{lcc}
\hline Ambientes & Temperatura média & Umidade média \\
\hline Estufa plástica & $30^{\circ} \mathrm{C}$ & $67 \%$ \\
Tela de sombreamento & $29^{\circ} \mathrm{C}$ & $64 \%$ \\
Céu aberto & $31^{\circ} \mathrm{C}$ & $61 \%$ \\
\hline
\end{tabular}

Cada parcela experimental foi constituída por 10 plantas. A semeadura foi realizada em sacos plásticos com capacidade de $1 \mathrm{~kg}$, preenchidos com solo e composto orgânico (esterco de curral curtido) na proporção de 3:2, respectivamente. O solo possuía as seguintes características físico-químicas: $\mathrm{pH}\left(\mathrm{CaCl}_{2}\right)=4,1, \mathrm{M} . \mathrm{O}=$ $12 \mathrm{~g} \cdot \mathrm{dm}^{-3}, \mathrm{P}$ (resina) $=9 \mathrm{mg} \cdot \mathrm{dm}^{-3} ; \mathrm{Al}^{+3}=6 \mathrm{mmol} \cdot \mathrm{dm}^{-3}, \mathrm{H}+\mathrm{Al}=40 \mathrm{mmolc} \cdot \mathrm{dm}^{-3}, \mathrm{~K}^{+}=$ 1,2 mmolc. $\mathrm{dm}^{-3}, \mathrm{Ca}^{2+}=7$ mmolc. $\mathrm{dm}^{-3}, \mathrm{Mg}^{2+}=2 \mathrm{mmolc} \cdot \mathrm{dm}^{-3}, \mathrm{SB}=50$ mmolc. $\mathrm{dm}^{-3} \mathrm{e}$ CTC $(\mathrm{T})=50$ mmolc. $\mathrm{dm}^{-3}$ e $\mathrm{V} \%=2 \%$. Já o composto orgânico possuía as seguintes características: $9,0 \%$ de $\mathrm{C}$ orgânico; $0,7 \%$ de $\mathrm{N}$ total; $0,8 \%$ de $\mathrm{P} ; 0,4 \%$ de $\mathrm{K} ; 1,1$ de $\mathrm{Ca} ; 0,2$ de $\mathrm{Mg}, \mathrm{pH}=8,0$.

As sementes de pata-de-vaca foram extraídas manualmente de frutos maduros oriundos, coletados abaixo da copa das árvores, de plantas presentes no Horto Medicinal, da Faculdade de Ciências Agrônomicas, Unesp Botucatu (2250 '36.38' 'S 4826 $08^{\prime}$ 'O). As sementes foram escarificadas, com lixa, e imersas ENCICLOPÉDIA BIOSFERA, Centro Científico Conhecer - Goiânia, v.13 n.23; p.52 2016 
em água por 48 horas para embebição, em seguida foram semeadas, colocando-se duas sementes por saco a uma profundidade de um $\mathrm{cm}$, e após três semanas foram realizados desbastes das plântulas. Foram realizadas regas periódicas com o auxilio de uma mangueira, sempre que necessário, e realizou-se limpeza dentro dos sacos, para retirar espécies indesejadas.

As mudas permaneceram nos ambientes por 75 dias. Conduziu-se as seguintes avaliações:

Porcentagem de emergência (PE): Obtida aos 28 dias após a semeadura, computando-se o número de plântulas normais, expressos em porcentagem.

Índice de velocidade de emergência (IVE): obtido a partir de contagens diárias de plântulas emergidas de acordo com MAGUIRE (1962).

Área foliar (AF): a edição foi realizada por meio de equipamento, Área Meter modelo $3100 \mathrm{LI}$, expresso em centímetros quadrado $\left(\mathrm{cm}^{2}\right)$.

Comprimento da raiz (CR): mensurado pela distância entre a parte apical e basal, sendo os resultados expressos em milímetros $(\mathrm{mm})$.

Comprimento da parte aérea (CPA): obtido pela distância entre a inserção da porção basal da raiz primária ao ápice da parte aérea, sendo os resultados expressos em milímetros $(\mathrm{mm})$.

Massa de matéria fresca da raiz, caule e folha (MFR, MFC e MFF): foram pesadas separadamente (por plântula) em balança digital, e os resultados expressos em gramas por plântula (g). Massa de matéria seca da raiz, caule e folha (MSR, MSC e MSF): as plântulas foram acondicionadas separadamente em sacos de papel e submetidas à secagem em estufa de ventilação forçada sob temperatura de $70^{\circ} \mathrm{C}$ até massa constante (72 horas), os resultados foram expressos em miligramas (mg) por plântula.

Volume da raiz (VR): foi determinada colocando-se as raízes individualmente em proveta graduada, contendo um volume conhecido de água, e pelo deslocamento do volume (diferença), obteve-se o volume de raízes, em mililitros $(\mathrm{mL})$.

Índice SPAD (SPAD): O monitoramento do índice SPAD (Soil Plant Analyzer Develop) foi obtido utilizando-se um clorofilômetro portátil (SPAD-502 Minolta Corp., Ramsey, Nova Jersey, EUA). Foram realizadas três leituras entre as 8 e 10 horas da manhã em três pontos distintos da folha mediana.

Os dados foram submetidos à análise de variância e as médias comparadas pelo teste Tukey a $5 \%$ de probabilidade.

\section{forficata Link.}

- Diferentes substratos na produção de mudas da espécie Bauhinia

Após a definição do ambiente mais satisfatório para a produção de mudas foi realizado um ensaio para estimar o efeito de diferentes substratos.

Seguiu-se a mesma metodologia descrita anteriormente em relação a coleta de frutos e extração de sementes.

A temperatura média do ambiente (estufa plástica) foi de $34,33{ }^{\circ} \mathrm{C}$ e a umidade relativa média de $61,90 \%$.

O delineamento experimental foi inteiramente casualizado com cinco tratamentos e quatro repetições, sendo cada parcela constituída por 10 plantas. Os tratamentos foram constituídos de diferentes substratos, 
sendo: Topstrato ${ }^{\circledR}$; Fibra de coco; Solo; Solo + Composto orgânico (esterco de curral curtido) na proporção de 3:2 (v/v) e Solo + Composto orgânico + Areia na proporção de 3:2:1 (v/v). Os resultados das análises de umidade, retenção hídrica, condutividade elétrica e $\mathrm{pH}$ dos substratos, encontram-se na Tabela 2.

TABELA 2. Umidade (UMID), retenção hídrica $(R H)$, condutividade elétrica (CE) e potencial hidrogeniônico $(\mathrm{pH})$ de diferentes substratos.

\begin{tabular}{|c|c|c|c|c|}
\hline Tipos de Substratos & $\begin{array}{l}\text { UMID } \\
(\%)\end{array}$ & $\begin{array}{l}\text { RH } \\
(\%)\end{array}$ & $\begin{array}{c}\text { CE } \\
\left(\mathrm{mS}^{\left.-\mathrm{cm}^{-1}\right)}\right)\end{array}$ & pH \\
\hline Topstrato $^{\circledR}$ & 78,00 & 34,50 & 1,1 & 5,0 \\
\hline Fibra de coco & 85,00 & 99,00 & 5,3 & 5,7 \\
\hline Solo & 9,50 & 33,50 & 3,0 & 5,6 \\
\hline Solo+Composto orgânico (3:2) & 25,00 & 53,00 & 3,4 & 5,6 \\
\hline Solo+Composto orgânico+Areia (3:2:1) & 23,00 & 40,00 & 3,3 & 5,6 \\
\hline
\end{tabular}

A semeadura ocorreu em sacos plásticos de um $\mathrm{kg}$, colocando-se duas sementes por saco, e após três semanas foram realizados desbastes das plântulas em excesso. A umidade dos substratos foi mantida com regas periódicas, sempre que necessário e realizou-se a limpeza dentro dos sacos. As mudas permaneceram nos ambientes por 75 dias, logo após procederam-se avaliações dos mesmos atributos descritos anteriormente (emergência, índice de velocidade de emergência, área foliar, comprimento de raiz, comprimento da parte aérea, massa de matéria fresca de raiz, caule, folha, massa de matéria seca da raiz, caule, folha, volume de raiz) de acordo com metodologias descritas anteriormente. Os dados foram submetidos à análise de variância e as médias comparadas pelo teste Tukey a $5 \%$ de probabilidade.

\section{RESULTADOS E DISCUSSÃO}

\section{- Diferentes ambientes na produção de mudas da espécie Bauhinia forficata Link.}

O ambiente de produção de mudas não afetou as seguintes características: porcentagem de emergência (PE), área foliar (AF), comprimento da raiz $(C R)$, massa de matéria fresca de raiz (MFR), caule (MFC) e folha (MFF), massa de matéria seca de caule (MSC) e volume da raiz (VR). As demais variáveis foram alteradas pelo ambiente de produção (Tabela 3).

Para o índice de velocidade de emergência (IVE), comprimento da parte aérea (CPA), massa de matéria seca da raiz (MSR) e da folha (MSF) os ambientes estufa plástica com $30 \%$ de sombreamento e tela de sombreamento de $50 \%$ foram os que propiciaram maiores valores para essas características, não diferindo entre si. O sombreamento não só auxiliou na rápida germinação da semente como também favoreceu maior crescimento tanto da parte aérea da planta quanto da raiz resultando assim no melhor desenvolvimento da espécie. A rápida emergência é característica desejável na produção de mudas, já que, isso proporciona menor exposição às condições adversas do meio na fase mais frágil de desenvolvimento da 
planta. E contribui para a diminuição do tempo em que a muda fica no viveiro, facilitando a logística e minimizando custos com a produção (LENHARD et al., 2013).

Os níveis de sombreamento dos ambientes protegidos favoreceram a diminuição da forte incidência da radiação solar, reduzindo os efeitos prejudiciais das altas temperaturas e taxas de evapotranspiração (OLIVEIRA \& GOMES FILHO, 2011). Esse prejuízo foi observado no ambiente céu aberto, que não possuiu nenhum tipo de proteção. Nele, obtiveram-se resultados inferiores aos demais ambientes. Isso também foi observado no estudo do desenvolvimento inicial das mudas de copaíba (Copaifera langsolosffii) sob influência de diferentes níveis de sombreamento. Os autores evidenciaram que a diminuição da incidência de luminosidade influenciou a taxa de crescimento das plantas e constataram que essa taxa foi menor no ambiente com alta incidência de luz (DUTRA et al., 2012). Resultados semelhantes também são relatados por CARVALHO FILHO et al. (2002) que estimaram o efeito de dois ambientes, diferentes misturas de substratos e dois tamanhos de recipientes no desenvolvimento de mudas de canafístula (Cassia grandis L.), e constataram que o ambiente protegido com tela sombrite $50 \%$ proporcionou os melhores resultados para a produção de mudas de canafístula, cultivadas nas misturas substrato solo + esterco em diferentes proporções.

\section{- Diferentes Substratos na produção de mudas da espécie Bauhinia forficata Link.}

Os diferentes substratos utilizados não propiciaram diferenças quanto à porcentagem de germinação (PG), índice de velocidade de emergência (IVE), área foliar (AF), comprimento da raiz (CR) e da parte aérea (CPA), massa de matéria fresca da raiz (MFR), caule (MFC) e folha (MFF). Para as características massa de matéria seca da raiz (MSR), massa de matéria seca do caule (MSC) e volume da raiz (VR) houve diferença entre os substratos utilizados (Tabela 4). Nestas características, o tratamento solo + composto orgânico + areia apresentou médias superiores, não diferindo dos substratos comerciais. É possível que a combinação de solo e areia e fonte orgânica tenha não só favorecido as propriedades físicas da mistura dos substratos, promovendo a porosidade e reduzindo a compactação, como também forneceu nutrientes essenciais que contribuiu para 0 bom desenvolvimento e crescimento das plântulas nessa fase inicial.

DUARTE et al. (2012) constataram aos 120 dias após a semeadura, o efeito de substrato composto orgânico + terra de subsolo (que apresentava alta quantidade de areia e silte) para as características altura das plantas, massa de matéria fresca da parte aérea e da raiz e massa de matéria seca da parte aérea para a produção de mudas de pata-de-vaca. Os autores relatam que isso deve ter acontecido devido à composição dos tratamentos como fonte orgânica, refletindo em maiores taxas de umidade, fornecimento de nutrientes e condições adequadas à germinação, desenvolvimento e crescimento das plântulas. CALDEIRA et al. (2008) avaliaram diferentes dosagens de composto orgânico na produção de mudas da aroeira pimenteira (Schinus terebinthifolius Raddi) e concluíram que as dosagens $20 \%, 40$, 60 e $80 \%$ de composto orgânico no substrato proporcionaram maior produção de massa seca da parte aérea. Enquanto que para massa de matéria seca da raiz, as 
dosagens com maior produção, foram a de $20 \%$ e $60 \%$.

\section{CONCLUSÃO}

Mudas de Pata-de-vaca necessita de sombra na sua fase inicial de desenvolvimento. A produção de mudas pode acontecer tanto no ambiente estufa fotosseletiva com a taxa de sombreamento a $30 \%$ quanto num telado com uma tela de sombreamento com malha de $50 \%$.

Em relação ao tipo de substrato indica-se a mistura de solo + composto orgânico + areia. 
TABELA 3. Emergência (EMERG), índice de velocidade de emergência (IVE); área foliar (AF); comprimento da raiz (CR); comprimento da parte aérea (CPA); massa de matéria fresca da raiz (MFR); massa de matéria fresca do caule (MFC); massa de matéria fresca da folha (MFF); massa de matéria seca da raiz (MSR); massa de matéria seca do caule (MSC); massa de matéria seca da folha (MSF); volume da raiz (VR) e SPAD, de mudas de pata-de-vaca (Bauhinia forficata Link) produzidas em diferentes ambientes.

\begin{tabular}{|c|c|c|c|c|c|c|c|c|c|c|c|c|c|}
\hline TRAT. & $\begin{array}{c}\text { EMERG }^{\text {ns }} \\
(\%)\end{array}$ & IVE & $\begin{array}{l}\mathrm{AF}^{\mathrm{ns}} \\
\left(\mathrm{cm}^{2}\right)\end{array}$ & $\begin{array}{l}\mathrm{CR}^{\mathrm{ns}} \\
(\mathrm{cm})\end{array}$ & $\begin{array}{l}\text { CPA } \\
(\mathrm{cm})\end{array}$ & $\begin{array}{c}\text { MFR }^{\text {ns }} \\
\text { (g) }\end{array}$ & $\begin{array}{c}\text { MFC }^{n s} \\
(g)\end{array}$ & $\begin{array}{l}\text { MFF ns }^{\text {(g) }}\end{array}$ & $\begin{array}{l}\text { MSR } \\
(\mathrm{mg})\end{array}$ & $\begin{array}{c}\mathrm{MSC}^{\mathrm{ns}} \\
(\mathrm{mg})\end{array}$ & $\begin{array}{l}\text { MSF } \\
(\mathrm{mg})\end{array}$ & $\begin{array}{l}V^{R^{n s}} \\
(m L)\end{array}$ & $\mathrm{SPAD}^{\mathrm{ns}}$ \\
\hline C.Aberto & 61,4 & $3,85 \mathrm{~b}$ & 14,81 & 14,44 & $4,24 \mathrm{~b}$ & 0,56 & 0,82 & 0,29 & $1,98 \mathrm{~b}$ & 0,96 & $1,12 b$ & 6,14 & 14,75 \\
\hline Telado & 67,1 & $5,14 a b$ & 17,77 & 18,10 & $6,20 \mathrm{a}$ & 0,42 & 0,78 & 0,25 & $\begin{array}{c}2,23 \\
a b\end{array}$ & 1,02 & $\begin{array}{c}1,19 \\
a b\end{array}$ & 6,14 & 14,78 \\
\hline Estufa & 75,7 & $5,57 \mathrm{a}$ & 16,40 & 18,85 & $6,47 \mathrm{a}$ & 0,51 & 1,06 & 0,31 & $2,95 \mathrm{a}$ & 1,40 & $1,75 a$ & 9,42 & 19,26 \\
\hline CV (\%) & 24,99 & 21,31 & 19,55 & 24,99 & 23,38 & 16,41 & 35,71 & 22,18 & 25,29 & 30,83 & 31,42 & 33,28 & 25,24 \\
\hline
\end{tabular}

${ }^{\text {ns }}$ não significativo.

Médias seguidas de mesma letra minúscula na coluna, não diferem entre si, pelo teste Tukey, ao nível de 5\% de probabilidade. 
TABELA 4. Porcentagem de emergência (PE); índice de velocidade de emergência (IVE); área foliar (AF); comprimento da raiz (CR); comprimento Da parte aérea (CPA); massa de matéria fresca da raiz (MFR); massa matéria do caule (MFC); massa de matéria fresca da folha (MFF); massa de matéria seca da raiz (MSR); massa de matéria seca do caule (MSC); massa de

\begin{tabular}{ccccccccccccc}
\hline TRAT. & $\begin{array}{c}\mathrm{PG}^{\mathrm{ns}} \\
(\%)\end{array}$ & $\begin{array}{c}\mathrm{IVE}^{\mathrm{ns}} \\
(\%)\end{array}$ & $\begin{array}{c}\mathrm{AF}^{\mathrm{ns}} \\
\left(\mathrm{cm}^{2}\right)\end{array}$ & $\begin{array}{c}\mathrm{CR}^{\mathrm{ns}} \\
(\mathrm{cm})\end{array}$ & $\begin{array}{c}\mathrm{CPA}^{\mathrm{ns}} \\
(\mathrm{cm})\end{array}$ & $\begin{array}{c}\text { MFR } \\
(\mathrm{g})\end{array}$ & $\begin{array}{c}\text { MFC } \\
(\mathrm{g})\end{array}$ & $\begin{array}{c}\text { MFF } \\
(\mathrm{g})\end{array}$ & $\begin{array}{c}\text { MSR } \\
(\mathrm{g})\end{array}$ & $\begin{array}{c}\text { MSC } \\
(\mathrm{g})\end{array}$ & $\begin{array}{c}\mathrm{MSF}^{\mathrm{ns}} \\
(\mathrm{g})\end{array}$ & $\begin{array}{c}\mathrm{VR}^{\mathrm{n}} \\
(\mathrm{mL})\end{array}$ \\
\hline Tropstrato ${ }^{\circledR}$ & 50 & 4,50 & 18,44 & 14 & 5 & 0,57 & 0,17 & 0,31 & $0,12 \mathrm{ab}$ & $0,06 \mathrm{ab}$ & 0,11 & $0,33 \mathrm{ab}$ \\
Fibra de coco & 30 & 3,48 & 13,91 & 9,5 & 4 & 0,57 & 0,26 & 0,25 & $0,08 \mathrm{ab}$ & $0,05 \mathrm{~b}$ & 0,09 & $0,30 \mathrm{~b}$ \\
Solo & 50 & 3,70 & 16,65 & 8,3 & 4 & 0,24 & 0,14 & 0,27 & $0,04 \mathrm{~b}$ & $0,04 \mathrm{~b}$ & 0,17 & $0,33 \mathrm{ab}$ \\
Solo+composto & 30 & 3,30 & 21,07 & 7,5 & 4,5 & 0,32 & 0,22 & 0,31 & $0,15 \mathrm{ab}$ & $0,10 \mathrm{a}$ & 0,05 & $0,61 \mathrm{ab}$ \\
Solo+composto+areia & 40 & 4,90 & 50,92 & 10,3 & 7,3 & 0,56 & 0,45 & 0,69 & $0,18 \mathrm{a}$ & $0,11 \mathrm{a}$ & 0,12 & $0,69 \mathrm{a}$ \\
\hline CV (\%) & 19,17 & 22,62 & 18,46 & 12,80 & 14,87 & 28,89 & 24,11 & 28,93 & 15,96 & 11,68 & 14,53 & 17,26
\end{tabular}

matéria seca da folha (MSF); volume da raiz (VR) de mudas de pata-de-vaca (Bauhinia forficata Link) produzidas com diferentes substratos, Botucatu, SP, 2013.

${ }^{\text {ns }}$ não significativo.

Médias seguidas de mesma letra minúscula na coluna, não diferem entre si, pelo teste Tukey, ao nível de 5\% de probabilidade 


\section{AGRADECIMENTOS}

À CAPES pelo auxílio financeiro.

\section{REFERÊNCIAS}

AGUIAR, F. F. A.; KANASHIRO, S.; TAVARES, A. R.; NASCIMENTO, T. D. R.; ROCCO,F. M. Crescimento de mudas de pau-brasil (Caesalpinia echinata Lam.), submetidas a cinco níveis de sombreamento. Revista Ceres, v. 58, n. 6, p.729-734, 2011. Disponível em: <http://dx.doi.org/10.1590/S0034-737X2011000600008>. doi: 10.1590/S0034-737X2011000600008

ALBUQUERQUE, M.C.F.; RODRIGUES, T.J.D.; MINOHARA, L.; TEBALDI, N.D.; SILVA, L.M.M. Influência da temperatura e do substrato na germinação de sementes de saguaraji (Colubrina glandulosa Perk. - Rhamnaceae). Revista Brasileira de Sementes, v.20, n.2, p.108-111, 1998.

ATROCH, E.M.A.C.; SOARES, A.M.; ALVARENGA, A.A.; CASTRO, E.M. Crescimento, teor de clorofilas, distribuição de biomassa e características anatômicas de plantas jovens de Bauhinia forficata Link submetidas à diferentes condições de sombreamento. Ciência e Agrotecnologia, v. 25, n. 4, p. 853-862, 2001.

BOENE, H. C. A. M.; NOGUEIRA, A. C.; SOUSA, N. J.; KRATZ, D.; SOUZA, P. V. D. Efeitos de diferentes substratos na produção de mudas de Sebastiania commersoniana. Revista Floresta, v. 43, n. 3, p.407-420, 2013.

CALDEIRA, M. V. W.; ROSA, G. N. da; FENILLI, T. A. B.; HARBS, R. M. P. Composto orgânico na produção de mudas de aroeira-vermelha. Scientia Agraria, v. 9, n. 1, p.2733, 2008.

COStA, E.; MESqUitA, G. A. V. do; LeAL, P. A. M; FERNANDES, C. D. ABOT, A. R. Formação de mudas de mamão em ambientes de cultivo protegido em diferentes substratos. Revista Ceres, v. 57, n. 5, p.679-685, 2010.

COSTA, E.; SANTOS, L. C. R. dos; CARVALHO, C. de.; LEAL, P. A. M.; GOMES, V. do A. Volumes de substratos comerciais, solo e composto orgânico afetando a formação de mudas de maracujazeiro-amarelo em diferentes ambientes de cultivo. Revista Ceres, v. 58, n. 2, p.216-222, 2011a. Disponível em: <http://dx.doi.org/10.1590/S0034-

737X2011000200013>. doi: 10.1590/S0034-737X2011000200013

COSTA, E.; DURANTE, L. G. Y; NAGEL, P. L.; FERREIRA, C. R.; SANTOS, A. dos. Qualidade de mudas de berinjela submetida a diferentes métodos de produção. Revista Ciência Agronômica, v. 42, n. 4, p.1017-1025, 2011b. Disponível em: < http://dx.doi.org/10.1590/S1806-66902011000400026>. doi: 10.1590/S180666902011000400026 
COSTA, V. P. da. Plantas medicinais utilizadas pela comunidade do bairro dos Tenentes município de Extrema, MG, Brasil. Revista Brasileira de Plantas Medicinais, v. 13, p.282-292, 2011. Disponível em: <http://dx.doi.org/10.1590/S1516-05722011000300006>. doi: 10.1590/S1516-05722011000300006

DUARTE, D. M; NUNES, U. R. Crescimento inicial de mudas de Bauhinia forficata Link em diferentes substratos. Revista Cerne, v. 18, n. 2, p. 327-334, 2012. Disponível em: < http://dx.doi.org/10.1590/S0104-77602012000200018>. doi: 10.1590/S010477602012000200018

FERRAZ, A. de V.; ENGEL, V. L. Efeito do tamanho de tubetes na qualidade de mudas de jatobá (Hymenaea courbaril L. VAR. stilbocarpa (HAYNE) LEE ET LANG.), ipê-amarelo (Tabebuia chrysotricha (MART. EX DC.) SANDL.) e guarucaia (Parapiptadenia rigida (BENTH.) BRENAN). Revista Árvore, v. 35, n. 3, p.413-423, 2011. Disponível em: <http://dx.doi.org/10.1590/S0100-67622011000300005>. doi: 10.1590/S010067622011000300005.

KOZLOWSKI, T.; KRAMER, P.J.; PALLARDY, S.G. The physiological ecology of woody plants. London: Academic Press, 657 p. 1991.

LELES, P.S.S.; ARAUJO, J.G.C.; BRITO, A.N.; GUERRA, D.B. Crescimento e arquitetura radicial de plantas de eucalipto oriundas de mudas produzidas em blocos prensados e em tubetes, após o plantio. Revista Ceres, v.7, n.1, p.010-019, 2001.

LENHARD, N. R. PAIVA NETO, V. B. de; SCALON, S. de P. Q.; ALVARENGA, A. A. de. Crescimento de mudas de pau-ferro sob diferentes níveis de sombreamento. Pesquisa Agropecuária Tropical, v. 43, n. 2, p.178-186, 2013. Disponível em: < http://dx.doi.org/10.1590/S1983-40632013000200012>. doi: 10.1590/S198340632013000200012

LOPES, J.L.W.; GUERRINI, I.A. SAAD, J.C.C.; SILVA, M.R. Atributos químicos e físicos de dois substratos para a produção de mudas de eucalipto. Revista Cerne, v.14, n.4, p. 358-367, 2006.

LÓPEZ, R. E. da S.; SANTOS, B. C. dos. Farmacologia: Bauhinia forficata Link (Fabaceae). Revista Fitos, v. 3, n. 9, p.161-252, 2015.

LORENZI, H. Árvores brasileiras: manual de identificação e cultivo de plantas arbóreas nativas do Brasil. Nova Odessa: Plantarum, 2002. 368 p.

LUSA M.G., BONA C. Análise morfoanatômica comparativa da folha de Bauhinia forficata Link e B. variegata Linn. (Leguminosae, Caesalpinioideae). Acta Botanica Brasilica. v.23, n.1, p.196-211, 2009.

MAGUIRE, J. Speed of germination-aid in selection and evaluation for seedling emergence and vigor. Crop Science, v.2, n.1, p. 176-177, 1962.

MARTINS, C. C.; NAKAGAWA, J.; BOVI, M. L. A. Efeito da posição da semente no substrato e no crescimento inicial das plântulas de palmito-vermelho (Euterpe espiritosantensis Fernandes - PALMAE). Revista Brasileira de Sementes, v. 21, n. 1, p.164-173, 1999. 
MATOS, F. S.; GAMBOA, I.; RIBEIRO, R. P.; MAYER, M. L.; NEVES, T. G; LEONARDO, B. R. L.; SOUZA, A. C. Influência da intensidade luminosa no desenvolvimento de mudas de Jatropha curcas L. Revista Agrarian, v. 4, n.1, p.265-272, 2011.

MORAIS, F.A.; GÓES, G.B.de; COSTA,M. E. da; MELO, I. G. C. e; VERAS, A. R. R.; CUNHA, G. O. de M. Fontes e proporções de esterco na composição de substratos para produção de mudas de jaqueira. Revista Brasileira de Ciências Agrárias - Brazilian Journal Of Agricultural Sciences, v. 7, n. 2012, p.784-789, 2012.

OLIVEIRA, A. B. de; GOMES FILHO, E. Ecofisiologia da germinação, estabelecimento de plantulas e produção de mudas: Discussão de Artigos científicos. Curitiba: Crv, 2011. $180 \mathrm{p}$.

LORENZI, H. Árvores brasileiras: manual de identificação e cultivo de plantas arbóreas nativas do Brasil. Nova Odessa: Plantarum, 2002. 368 p

POPINIGIS, F. Fisiologia de sementes. Brasília: AGIPLAN, 1977. 289p.

SANTOS, T. M. dos; RIEDER, A. Plantas do gênero Bauhinia e suas potencialidades hipoglicemiante e antidiabética: um estudo analítico. Revista Citino: Ciência, Tecnologia, Inovação e Oportunidade, v. 3, n. 2, p.35-48, 2013.

SILVA, José M.; FERREIRA, R. S.; MELO, A. S. de; SUASSUNA, J. F.; DUTRA, A. F.; GOMES, J. P. Cultivo do tomateiro em ambiente protegido sob diferentes taxas de reposição da evapotranspiração. Revista Brasileira de Engenharia Agrícola e Ambiental, v. 17, n. 1, p.40-46, 2013.

SILVA, R. F.; SAIDELLES, F. L. F.; KEMERICH, P. D. C.; STEFFEN, R. B.; SWAROWSKY,A.;SILVA, A. S. da Crescimento e qualidade de mudas de Timbó e Dedaleiro cultivadas em solo contaminado por cobre. Revista Brasileira de Engenharia Agrícola e Ambiental, v. 16, n. 8, p.881-886, 2012.

SIMÕES, R.C.; ALMEIDA, S.S.M.S. Estudo Fitoquímico de Bauhinia forficata (Fabaceae). Biota Amazônia, v. 5, n. 1, p.27-31, 2015. Disponível em: < http://dx.doi.org/10.18561/2179-5746>. doi: 10.18561/2179-5746

TAIZ, L.; ZEIGER, E. Fisiologia vegetal. 3. ed. Porto Alegre: Artmed, 2004. 719 p.

TRES, D. R.; REIS, A. Técnicas nucleadoras na restauração de floresta ribeirinha em área de Floresta Ombrófila Mista, Sul do Brasil. Biotemas, v. 22, n. 4, p.59-71, 2009. Disponível em: <https://periodicos.ufsc.br/index.php/biotemas/article/view/21757925.2009v22n4p59/17649>.

VIANA, J.S.; GONÇALVES, E.P.; ANDRADE, L.A.; OLIVEIRA, L.S.B.; SILVA, E.O. Crescimento de mudas de Bauhinia forficata Link. em diferentes tamanhos de recipientes. Revista Floresta, v.38, n.4, p. 663-671, 2008. 